\title{
The knowledge of the doctor just formed on the approach to the airway and the importance of practical theoretical courses on this field.
}

Abrão, MA; Lopes, F; Peclat, T; Leite, S.

\section{Background and Goal of Study}

Cardiovascular events and external causes are important indicators of death among Brazilian population. In this context, mask ventilation and orotracheal intubation are considered lifesaving procedures. However, the level of such knowledge is not satisfactory, even among the most qualified professionals, and in hospitals with medical residency programs, it is often the case that physicians in training are responsible for this first service. As for medical teaching, learning techniques with simulations of real situations are now used. The objective of this study was to apply simulation practice in airway management to residents' level one and to evaluate their outcome.

\section{Materials and Methods}

Newly graduated from medical school and current first year of internal medicine and general surgery residents were invited to the study. A theoretical pre-test was applied to all participants, followed by a theoretical lecture and theoretical post-test. After one month, the participants were distributed in groups and then submitted to a validated practical assessment, followed by a practical class with manikins. Then a reassessment of the practical and theoretical test was applied. The participant who scored a grade equal to or greater than 15 was defined as competent. In the theoretical test, a grade greater than or equal to 7 was considered satisfactory. For the analysis of the nonparametric data, the Wilcoxon flagged test and the Friedman ANOVA were used. The qualitative variables were analyzed using the McNemar test. The value of $p<0.05$ was considered significant.

1st Stage

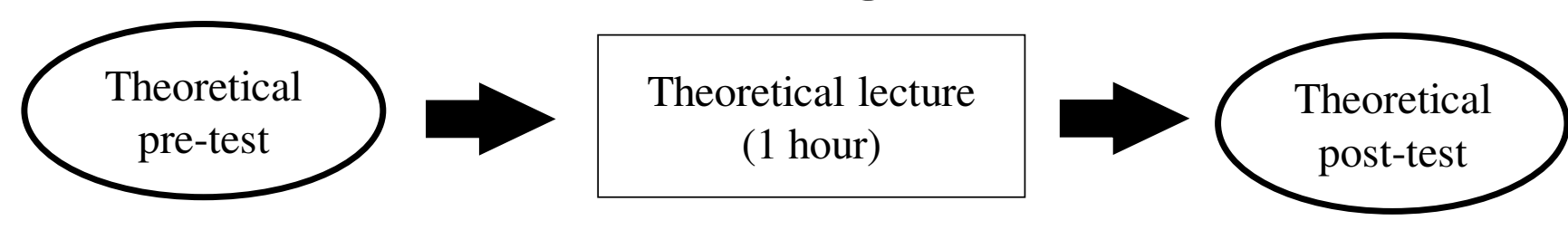

\section{2nd Stage}

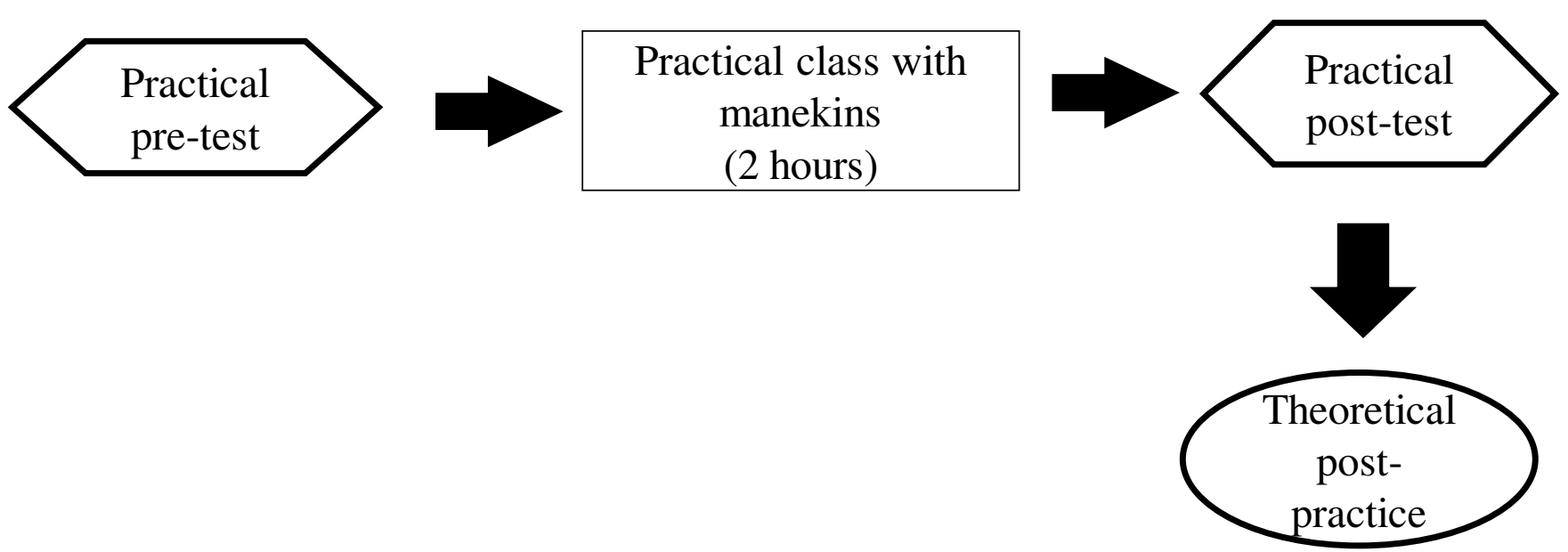

Figure 1: Study Method.

\section{Results and Discussion}

Of the 31 invited residents, 25 were accepted. Of these, 1 was excluded, 24 had the practical data analyzed and 22 the theoretical data. The competence of the professionals in the practical assessment increased from $20.8 \%$ to $87.5 \%$ at the end of the course $(p<0.0001)$, demonstrating the acquisition of knowledge and a significant and important improvement in the residents' performance. In the theoretical evaluation, the number of students with satisfactory results jumped from $13.6 \%$ to $63.8 \%$ between the pre- and post-test, in addition to the $68.1 \%$ in the test after the practice $(p<0.0001)$, suggesting not only the improvement of knowledge, but also its maintenance.

\begin{tabular}{lcccc}
\multicolumn{2}{l}{ Practical test } & \multicolumn{2}{c}{ Pos-test } & Total \\
& $\mathrm{NC}(\mathrm{n} / \%)$ & $\mathrm{C}(\mathrm{n} / \%)$ & $(\mathrm{n} / \%)$ \\
\hline Pre-test & $\mathrm{NC}(\mathrm{n} / \%)$ & $3 / 12.5 \%$ & $16 / 66.7 \%$ & $19 / 79.2 \%$ \\
& $\mathrm{C}(\mathrm{n} / \%)$ & $0 / 0 \%$ & $5 / 20.8 \%$ & $5 / 20.8 \%$ \\
\hline \multicolumn{2}{c}{ Total $(\mathrm{n} / \%)$} & $3 / 12.5 \%$ & $21 / 87.5 \%$ & $24 / 100 \%$ \\
\hline
\end{tabular}

Table 1: Performance on the practical test. (C-competent; $N C$-not competent)

\section{Conclusion}

Our study demonstrated that the application of a theoretical and practical course of approach to airway for newly graduated medical school students improved their performance in this field.

\section{References}

1) Reichenheim ME, Souza ER, Moraes CL, Mello Jorge MHP, Silva CMFP, Minayo MCS. Violência e lesões no Brasil: efeitos, avanços alcançados e desafios futuros. The Lancet. [online]. 2011 (75-89). http://download.thelancet.com/flatcontentassets/pdfs/brazil/brazilpor 5.pdf

2) Link MS, Berkow LC, Kudenchuk PJ, Halperin HR, Hess EP, Moitra VK, Neumar RW, O'Neil BJ, Paxton JH, Silvers SM, White RD, Yannopoulos D, Donnino MW. Part 7: adult advanced cardiovascular life support: 2015 American Heart Association Guidelines Update for Cardiopulmonary Resuscitation and Emergency Cardiovascular Care. Circulation 2015; 132 (suppl 2):S444-S464.

3) Jérémie N, Seltzer S, Lenfant F, Ricard-Hibon A, Facon A, Cabrita B, et al. Rapid sequence induction: a survey of practices in three French prehospital mobile emergency units. Eur J Emerg Med. 2006;13(3):14855.

4) McGraw RC. Testing the Validity of an Assessrnent Process for Aiway Management Skills. Tese [Doutorado em Educação] - Queen's University, Kingston, Ontario; 2000.

5) Kuduvalli PM, Jervis A, Tighe SQM e Robin NM. Unanticipated difficult airway management in anaesthetized patients: a prospective study of the effect of mannequin training on management strategies and skill retention. Anaesthesia 2008; 63:364-9. 